\title{
Assessment of patterns of cognitive impairment in diabetic patients a retrospective case-control study
}

\author{
Hazem Kamal Elhewag, Ahmed Borai. \\ Department of Neuropsychiatry, Faculty of Medicine, Sohag University, Egypt
}

\begin{abstract}
:
Background: Cognitive dysfunction is common complaints among diabetic patients their occurrence emanate a great topic during the illness, so our study aimed to examine the occurrence and the pattern of executive dysfunctions in patients with type $2 \mathrm{DM}$.

Methods: 40 patients with type 2 diabetes mellitus matched with 40 control subjects by age, sex, and educational level. They were examined for executive functions by event-related potentials (P300) and executive functions battery

Results: patients with type 2 DM showed significantly affected P300 regarding both latency and amplitude. When using the executive functions battery, it showed deficits in most of the executive function tests with a significant difference between cases and control groups. There was a significant relationship between poor cognitive scores in diabetic patients and P300. Also, a significant positive correlation detected between poor scores of cognitive function tests in diabetic patients and poor glycemic control detected byHbA1c.

Conclusion: Type 2 diabetes is associated with accelerated cognitive decline and an increased risk of dementia, particularly in older individuals. Our findings suggest that surface-recorded ERPs and executive functions battery is useful for determining and follow up the changes in brain function associated with diabetes mellitus, appropriate management, and treatment of type 2 diabetes mellitus could prevent the onset and progression of mild cognitive impairment to dementia so executive function battery could be more beneficial and significant than P300 in the assessment of diabetes mellitus related cognitive impairment.
\end{abstract}

Keywords: Executive functions, Type 2 DM, cognition in diabetes.

\section{List of abbreviation}

ERPs event-related potential, HbAlc; Glycosylated hemoglobulin, FBS, Fasting blood sugar in mmol, TMT; Trail Making Test, BMI; body mass index, DM diabetes Miletus, MRI; magnetic resonance image, DR; Diabetic retinopathy

\section{Introduction}

In the last decade, the relation of diabetes to memory disorders has been well established, diabetes mellitus is a metabolic disorder affecting multiple organs including the brain ${ }^{1}$.Type 2 diabetes Mellitus is more prevalent in elderly patients who are also at a higher risk for dementia and cognitive dysfunction $^{2}$ one of the established risk factors for cognitive impairment is type two diabetes mellitus. ${ }^{3,4}$ This association may be due to insulin resistance which indirectly damages the brain and/or secondary to vascular changes. Also, insulin receptors are found abundantly in certain brain areas as the hippocampus and amygdala which play an important role in memory and learning ${ }^{5}$. Neuropathological researches and imaging proved the role of diabetes in the degeneration of the nervous system, brain atrophic changed are found in magnetic resonance image of diabetic patients6 up to three-fold acceleration 
of this atrophy in comparing to nor$\mathrm{mal}^{7,8}$

Early detection of cognitive impairment in patients with type two diabetes mellitus allows effective treatment and prevents the progression of neuropathological changes ${ }^{9}$. Unfortunately, early detection of cognitive impairment is usually missed because most physicians pay attention to glycemic control and the detection of other diabetic complications as nephropathy and retinopathy.

Diabetic retinopathy is a good predictor of cognitive dysfunction due to the similarity between small vessels and retinal vasculature ${ }^{10 .}$ The risk of cognitive impairment is threefold in a patient with diabetic retinopathy however the severity of impairment with diabetic retinopathy is not clearly illustrated, another study found a significant correlation between cognitive impairment and diabetic retinopathy in severity in men. The recent memory and verbal learning were the most defective cognitive domains in these studies ${ }^{11}$.

In this study, we aimed to identify the pattern and the risk factors of cognitive impairment in patients with type 2 diabetes mellitus using the neurocognitive battery and event-related potential (P300).

\section{Patients and methods}

Our study is a retrospective case-control study carried out at the neurology department, Sohag University Hospital and the local ethical committee approved the study. This study included forty patients with type 2 diabetes mellitus and forty control subjects with average educational level, who attended to Sohag University Hospital, Department of neu-rology and psychological medicine, and outpatient clinic from June 2017 to June 2018. We excluded patients with a documented history of other neurological diseases which might affect the cognition, patients with metabolic disorders which may affect the cognition as liver cirrhosis, patients with comorbid psychiatric illness, patients with a mini-mental state examination score less than 24 , and patients who can't respond the neurocognitive battery or the eventrelated potential (P300).

The following data has been extracted from participant records: event-related potential (P300) parameters and executive function battery results: the battery from The Psychology experiment building language (Version 0.13) [Software $]^{12,13}$. From these tests, the following tests result were chosen :

1-Set shifting by Wisconsin Card Sorting Test ${ }^{14}$ 2-Working memory by digit span test ${ }^{15} 3$-Planning by a) Tower of London: ${ }^{16}$ b) Trail Making Test: is done .4-Attention by continuous performance tests. ${ }^{17}$ 5-Visuospatial by The Corsi block-tapping test ${ }^{18}$

\section{Statistical Analysis}

SPSS version 24 was used for data analysis, Quantitative data were represented as mean, standard deviation, median, and range. Data were analyzed using the Mann-Whitney test instead of the standard t-test. Qualitative data were presented as number and percentage and compared using either a Chi-square test in normal distributed data or fisher exact test if not normally distributed. Pvalue was considered significant if it was less than 0.05 .

\section{Results:}

The mean age for patients was $55.62 \pm$ 4.049. Most of the patients were males with a mean duration of illness of $4.754 .75 \pm 2.72$ years. Differences between cases and controls in glucose concentrations and Hb1Ac. Cases were significantly higher concentrations of FBG, $\mathrm{PBG}$, and $\mathrm{HbA} 1 \mathrm{c}$ in comparison to controls as follows mean \pm SD $(9.35$ \pm 2.55 vs $4.30 \pm 0.71),(12.69 \pm 2.39$ vs $5.37 \pm 0.59)$ and $(7.76 \pm 0.94$ vs $5.058 \pm 1.27)$. respectively, patients also 
SOHAG MEDICAL JOURNAL Vol. 24 No. 3 July 2020 had significantly higher BMI than control with cases mean \pm SD 30.27 \pm 4.57 in contrast to controls mean 25.05 $\pm 4.42 \mathrm{P}$-value was 0.001 .

In our study, most of the patients were on oral hypoglycemic $60 \%$. In compar- eson to controls Patients were significantly higher mean \pm SD p300 latency $(342.61 \pm 30.98$ vs $328.12 \pm 23.98)$ and amplitude $(8.09 \pm 2.784$ vs $7.43 \pm 3.97)$ with $\mathrm{p}$ value $<0.0001$. (Table 1 )

\begin{tabular}{|c|c|c|c|}
\hline Variable & Case $(n=40)$ & Control $(n=40)$ & $\mathrm{P}$ value \\
\hline \multicolumn{4}{|l|}{ Patient characteristics } \\
\hline Gender, Male & 21 & 15 & 0.178 \\
\hline Age/years Mean \pm SD & $55.62 \pm 4.049$ & $55.67 \pm 3.912$ & 0.9550 \\
\hline $\begin{array}{l}\text { Duration of illness/year Mean } \pm \text { SD } \\
\text { Range }\end{array}$ & $\begin{array}{l}4.750 \pm 2.72 \\
1-10\end{array}$ & & \\
\hline \multicolumn{4}{|l|}{ Blood glucose tests and treatment } \\
\hline HbA1c, Mean \pm SD & $7.760 \pm 0.943$ & $5.058 \pm 1.270$ & 0.001 \\
\hline FBS, Mean \pm SD & $9.35 \pm 2.55$ & $4.30 \pm 0.71$ & 0.0001 \\
\hline $\begin{array}{l}\text { Postprandial blood glucose;mmol Mean } \\
\pm \text { SD }\end{array}$ & $12.69 \pm 2.39$ & $5.37 \pm 0.59$ & 0.0001 \\
\hline $\begin{array}{l}\text { Type of treatment among cases } \\
\text { (oral hypoglycemic) } \\
\text { (insulin) }\end{array}$ & $\begin{array}{l}24(60 \%) \\
16(40 \%) \\
\end{array}$ & & \\
\hline BMI, Mean \pm SD & $30.275 \pm 4.5797$ & $25.050 \pm 4.4199$ & 0.001 \\
\hline \multicolumn{4}{|l|}{ P300 latency and Amplitude } \\
\hline P300 Latency; msec & $\begin{array}{l}279.00-600.0 \\
342.61 \pm 30.98 \\
\end{array}$ & $\begin{array}{l}276.00-363.00 \\
328.12 \pm 23.98 \\
\end{array}$ & 0.0001 \\
\hline P300 amplitude; mv & $\begin{array}{l}1.20-17.80 \\
8.09 \pm 2.784 \\
\end{array}$ & $\begin{array}{l}6.81-19.12 \\
7.43 \pm 3.97 \\
\end{array}$ & 0.0001 \\
\hline \multicolumn{4}{|l|}{ Wisconsin Test } \\
\hline Total errors No, Mean \pm SD & $26.684 \pm 8.111$ & $26.475 \pm 13.301$ & 0.934 \\
\hline Preservative errors $\%$ Mean \pm SD & $20.27 \% \pm .18 \%$ & $7.70 \% \pm 7.50 \%$ & 0.001 \\
\hline \multicolumn{4}{|l|}{ Tower of London test } \\
\hline Total time, Mean \pm SD & $748.342 \pm 284.273$ & $14.473 \pm 43.650$ & 0.001 \\
\hline \multicolumn{4}{|l|}{ Trail Making Test } \\
\hline TMT-A (total time), Mean \pm SD & $47.30 \pm 16.85$ & $40.75 \pm 12.49$ & 0.03 \\
\hline TMT-B (total time), Mean \pm SD & $103.48 \pm 54.29$ & $82.78 \pm 28.10$ & 0.01 \\
\hline Accuracy & $0.631 \pm 0.191$ & $0.821 \pm 0.108$ & 0.001 \\
\hline Extra moves & $49.00 \pm 15.52$ & $29.54 \pm 18.74$ & 0.001 \\
\hline \multicolumn{4}{|l|}{ Continuous performance test } \\
\hline Correct trials, Mean \pm SD & $287.037 \pm 60.080$ & $322.725 \pm 31.177$ & 0.002 \\
\hline Commission, Mean \pm SD & $16.630 \pm 6.301$ & $18.625 \pm 6.364$ & 0.211 \\
\hline Omission, Mean \pm SD & $56.370 \pm 65.280$ & $12.300 \pm 12.089$ & 0.001 \\
\hline \multicolumn{4}{|l|}{ Corsi test and Digit span test } \\
\hline Corasi test (memory span) Mean \pm SD & $2.438 \pm 1.001$ & $3.863 \pm 1.891$ & 0.001 \\
\hline $\begin{array}{l}\text { Digital span test } \\
\text {-Forward, Mean } \pm \text { SD } \\
\text {-Backward, Mean } \pm \text { SD }\end{array}$ & $\begin{array}{l}5.175 \pm 1.217 \\
3.50 \pm 1.00 \\
\end{array}$ & $\begin{array}{l}6.863 \pm 1.506 \\
4.67 \pm 2.15 \\
\end{array}$ & 0.001 \\
\hline
\end{tabular}

Table1; Demographic data, Boog glucose level and cognitive tests between the two groups .

HbAlc Glycosylated hemoglobulin, FBS, Fasting blood sugar in mmol, TMT; Trail Making Test, MI; body mass index 


\section{Executive function battery:}

1 -Wisconsin test comparisons of executive functions among the two groups suggest a significant difference between diabetic $20.27 \% \pm 7.18 \%$ and normal groups $7.70 \% \pm 7.50 \%$ in WCST (perseveration) $\mathrm{p}$-value $=0.001$, and a significant difference between diabetic and control in WCST (category) pvalue $=0.001$. But there was no significant difference between the two groups in (Total errors).

2-Tower of London test showed a significant difference in total time between cases with mean $748.342 \pm 284.27$ while in control $167.240 \pm 14.47$. Also showed a significant difference between two groups in extra moves p-value $=0.001$.

3-Trail Making test statistically significant differences were observed between patients and controls in the total time TMT part A (0.03), TMT part B (0.01). Also, a significant difference was seen between cases and control in accuracy and extra moves.

4-Continuous performance test cases made significantly more omission errors than control (p-value $=0.001)$ and correct trials are significantly more at cases than controls, while commission errors are non-significantly increased in cases $16.63 \pm 6.301$ than in control subjects $18.625 \pm 6.364$.

5-Corasi test which assesses visuospatial short-term working memory showed a significant difference in memory span among cases with a mean \pm SD ( 2.438 \pm 1.001$)$ and control(3.863 \pm 1.891 .) Also, the digit

\begin{tabular}{|l|l|l|l|l|l|}
\hline ERPs variables(p300). & Age(years) & $\begin{array}{l}\text { Duration of } \\
\text { diabetes }\end{array}$ & \multicolumn{3}{|c|}{ Diabetic control (HbA1c) } \\
\cline { 4 - 6 } & & Good & poor & P value \\
\hline P300Latency; msec & $\begin{array}{l}0.638 \\
(\mathrm{p}=0.01)\end{array}$ & $\begin{array}{l}0.398 \\
(\mathrm{p}=0.158)\end{array}$ & 5.8 & 4.4 & 0.002 \\
\hline P300 amplitude; mv & $\begin{array}{l}0.382 \\
(\mathrm{p}=0.17)\end{array}$ & $\begin{array}{l}0.397 \\
(\mathrm{p}=0.160)\end{array}$ & 3.7 & 2.1 & 0.303 \\
\hline
\end{tabular}

Table3 Patient correlation between ERPs variables (p300), age of the patient

ERPs event-related potential, HbAlc; Glycosylated hemoglobulin, 


\section{Discussion}

Our study determined the impact of type II diabetes mellitus on cognition by using neurophysiological and neuropsychological tools (executive function battery) and this in line with Biessels and Despa., $2018^{26}$

Little studies were done in this aspect and all were discussing the clinical assessment of cognitive impairment in diabetes. Researchers considered one of the important risk factors for cognitive impairment in diabetes mellitus ${ }^{19,27}$ while others disagreed for this ${ }^{20}$. These two different results are because of chronic hyperglycemia with other vascular risk factors for microvascular and macrovascular disease and atherosclerosis ${ }^{21}$.

Little is known about the effect of hyperglycemia in cerebral tissue in the patient without other vascular risk factors, in our research, we confirmed the risk of cognitive dysfunction with type 2 diabetes mellitus as follows, diabetic patients had low results in cognitive testing and also hardly performing different cognitive tasks: as set shifting, working memory, attention, planning, visuospatial and associate learning. Consistent with expectations, cognitive dysfunction was common in this sample of people with type 2 diabetes. Performance on every classical executive test included in the battery was significantly different between cases and controls for example the results show that there was a significant differrence among normal and diabetic groups in the executive function of WCST (perseveration) and information processing. In other words, the performance of the diabetic group was lower than the other control group. This finding was concordant with the reports ${ }^{22}$. Trail making test shows significant differences were observed between patients and controls in the total time, accuracy and extra moves in agreement with also tower of London test showed significant difference among diabetic and controls.
This finding was in line with another study $^{23}$ Continuous performance test showed increased omission errors (failing to respond to targets) and correct trial among cases than control while commission errors (responding to non-targets) showed no significant difference between diabetic and nondiabetic. Cognitive test outcomes, includeing digit span and corsi blocktapping, showed a significant difference between the diabetic and controls these finding agreed with ${ }^{24}$

P300 of diabetic patients had decreased amplitude in comparing to control group $(\mathrm{p}<0.0001)$ and had increased in latency $(\mathrm{p}<0.0001)$ representing cognitive dysfunction of diabetic patient ${ }^{25,28}$ Our study found that executive function battery could be more beneficial and significant than P300 in assessment diabetes mellitus related cognitive impairment, as the battery is not only quantitative but also qualitative as it can assess the pattern of cognitive abnormality with type $2 \mathrm{DM}$ and this could not be detected through P300.

\section{Conclusion}

Progressive cognitive impairment and increases in dementia risk are associated with elderly diabetic patients. Surface-recorded ERPs and the executive functions battery is useful for determining and follow up the changes in brain function associated with diabetes mellitus, also appropriate management and treatment of type 2 diabetes mellitus could prevent the onset and progression of mild cognitive impairment to dementia, executive function battery could be more beneficial and significant than P300 in assessment diabetes mellitus related cognitive impairment

\section{Acknowledgments}

Not applicable

\section{Funding}

None. 


\section{Authors' contributions}

HKE choose the research idea, HKE, and $\mathrm{AB}$ sharing the development plan, HKE conducting and applying the research, $\mathrm{HKE}$ and $\mathrm{AB}$ participate in data analysis and discussion, $\mathrm{AB}$ participate writing the paper and HKE participate in research review, all authors read and approved the final manuscript.

\section{Competing interests, No}

\section{References:}

1.Miles WR, Root HF. Psychologic tests applied to diabetic patients. Arch Intern Med 2003; 30:767-777.

2. Strachan MW. R D Lawrence Lecture.The brain as a target organ in type 2 diabetes: exploring the links with cognitive impairment and dementia. Diabet Med. 2001; 28:141-7.

3. Cukierman T, Gerstein HC, Williamson JD. Cognitive decline and dementia in diabetes - systematic overview of prospective observational studies. Diabetologia 2005; 48:2460-2469.

4. Arvanitakis Z, Wilson RS, Bienias JL, Evans DA, Bennett DA. Diabetes mellitus and risk of Alzheimer's disease and decline in cognitive function. Arch Neurol 2004; 61:661-666.

5. Brenna Cholerton, Laura D. Baker, Thomas J. Montine, Suzanne Craft. Type 2 Diabetes, Cognition, and Dementia in Older Adults: Toward a Precision Health Approach. Diabetes Spectrum 2016; 29(4): 210-219.

6. Moran C, Phan TG, Chen J, Blizzard L, Beare R, Venn A, et al. Brain atrophy in type 2 diabetes: regional distribution and influence on cognition. Diabetes Care. 2013; 36:4036-4042.

7. Kooistra M, Geerlings MI, Mali WP, Vincken KL, van der Graaf Y, Biessels GJ. Diabetes mellitus and progression of vascular brain lesions and brain atrophy in patients with symptomatic atherosclerotic disease. The SMART-MR study. J Neurol Sci. 2013; 332:69-74.

8. van Elderen SG, de Roos A, de Craen AJ, Westendorp RG, Blauw GJ, Jukema JW, Progression of brain atrophy, and cognitive decline in diabetes mellitus: a 3-year follow-up. Neurology. 2010; 75:9971002.

9. Ghasemi R, Haeri A, Dargahi L, Mohamed $\mathrm{Z}$, Ahmadiani A Insulin in the brain: sources, localization, and functions. Mol Neurobiol 2013; 47:145-171.

10. Patton N, Aslam T, Macgillivray T, Pattie A, Deary IJ, Dhillon B. Retinal vascular image analysis as a potential screening tool for cerebrovascular disease: a rationale based on homology between cerebral and retinal microvasculatures. J Anat. 2005; 206:319-348.

11. Crosby-Nwaobi R, Sivaprasad S, Forbes A. A systematic review of the association of diabetic retinopathy and cognitive impairment in people with Type 2 diabetes. Diabetes Res Clin Pract. 2012; 96:101110.

12. Mueller ST. The PEBL Manual, Version 0.13. Lulu Press. 2012 ISBN 9780557658176.http://www.lulu.com/shop/sh ane-t-mueller/thepebl- manual/paperback/product20595443.html

13. Mueller ST. "Developing open-source tests for psychology and neuroscience." 2012 Dec; Feature at opensource.com, http://opensource.com/lif e/12/12/developing-open-sourcetests- psychology-and-neuroscience.

14. Berg EA. A simple objective technique for measuring flexibility in thinking. J Gen Psychol 1948; 39:15-22.

15. CelesteD.Lefebvrea YannickMarchandab Gail A.EskesacJohn F.Connolly. Assessment of working memory abilities using an event-related brain potential (ERP)-compatible digit span backward task. Clinical Neurophysiology.Volume 116, Issue 7, July 2005, Pages 1665-1680

16. Craig A. Knoblock. Automatically Generating Abstractions for Problem Solving. Ph.D. thesis, School of Computer Science, Carnegie Mellon University, 1991. Available as Technical Report CMUCS-91-120.

17. Conners CK. MHS Staff. Conners' Continuous Performance Test II: computer program for windows technical guide and software manual. North Tonawanda, NY: Multi-Health Systems; 2000.

18. Kessels, R. P. C.; van Zandvoort, M. J. E.; Postma, A.; Kappelle, L. J.; de Haan, E. H. 
F (2000). "The Corsi Block-Tapping Task: Standardization and Normative Data". Applied Neuropsychology. 7 (4): 252-258.

19. Cosway R, Strachan MW, Dougall A, Frier BM, Deary IJ. Cognitive function and information processing in type 2 diabetes. Diabet Med 2001;18(10):803-810.

20. Awad N, Gagnon M, Messier C. The relationship between impaired glucose tolerance, type 2 diabetes, and cognitive function. J Clin Exp Neuropsychol 2004;26(8):1044-1080.

21.Bekyarova GY, Ivanova DG, Madjova VH. Molecular mechanisms associating oxidative stress with endothelial dysfunction in the development of various vascular complications in diabetes mellitus. Folia Med (Plovdiv) 2007;49(3-4):13-19.

22.Marzieh Nazaribadie, Masoud Amini, Mohammad Ahmadpanah, Karim Asgari, Somaye Jamlipaghaleand Sara Nazaribadi. Journal of Diabetes \& Metabolic Disorders 2014, 13:2

23. Annalia Marchegiani, Marie V. Giannelli \&Patrizio R. Odette 10- Pages 155-158 | Received 20 Apr 2009, Accepted 28 Jul 2009, Published online: 24 Nov 2009.

24.Kessels RPC, Van den Berg E, Ruis C, Brands AMA. The backward span of the
Corsi Block-Tapping Task and its association with the WAIS-III Digit Span. Assessment 2008; 15:426-434.

25.Kurita A, Mochio S, Isogai Y. Changes in auditory P300 event-related potentials and brainstem evoked potentials in diabetes mellitus. Acta Neurol Scand 1995;92(4):319-323

26.Biessels and Despa; Cognitive decline and dementia in diabetes: mechanisms and clinical implications Nat Rev Endocrinol. 2018 October; 14(10): 591-604. DOI:10.1038/s41574-018-0048-7.

27.Saedi E, Gheini MR, Faiz F, Arami MA. Diabetes mellitus and cognitive impairments. World J Diabetes 2016; 7(17): 412-422 Available from URL: http://www.wjgnet.com/19489358/full/ v7/i17/412.htm DOI: http://dx.doi.org/10.4239/wjd.v7.i17. 412

28. Elisabeth Andreadou, Asimina Mitrakou, Vasilios-Costas Constantinides, Nikolaos Triantafyllou.; Auditory P300 event-related potentials in patients with type 2 diabetes mellitus, Journal of Diabetes Research and Clinical Metabolism March 2012, DOI: 10.7243/2050-0866-1-1 